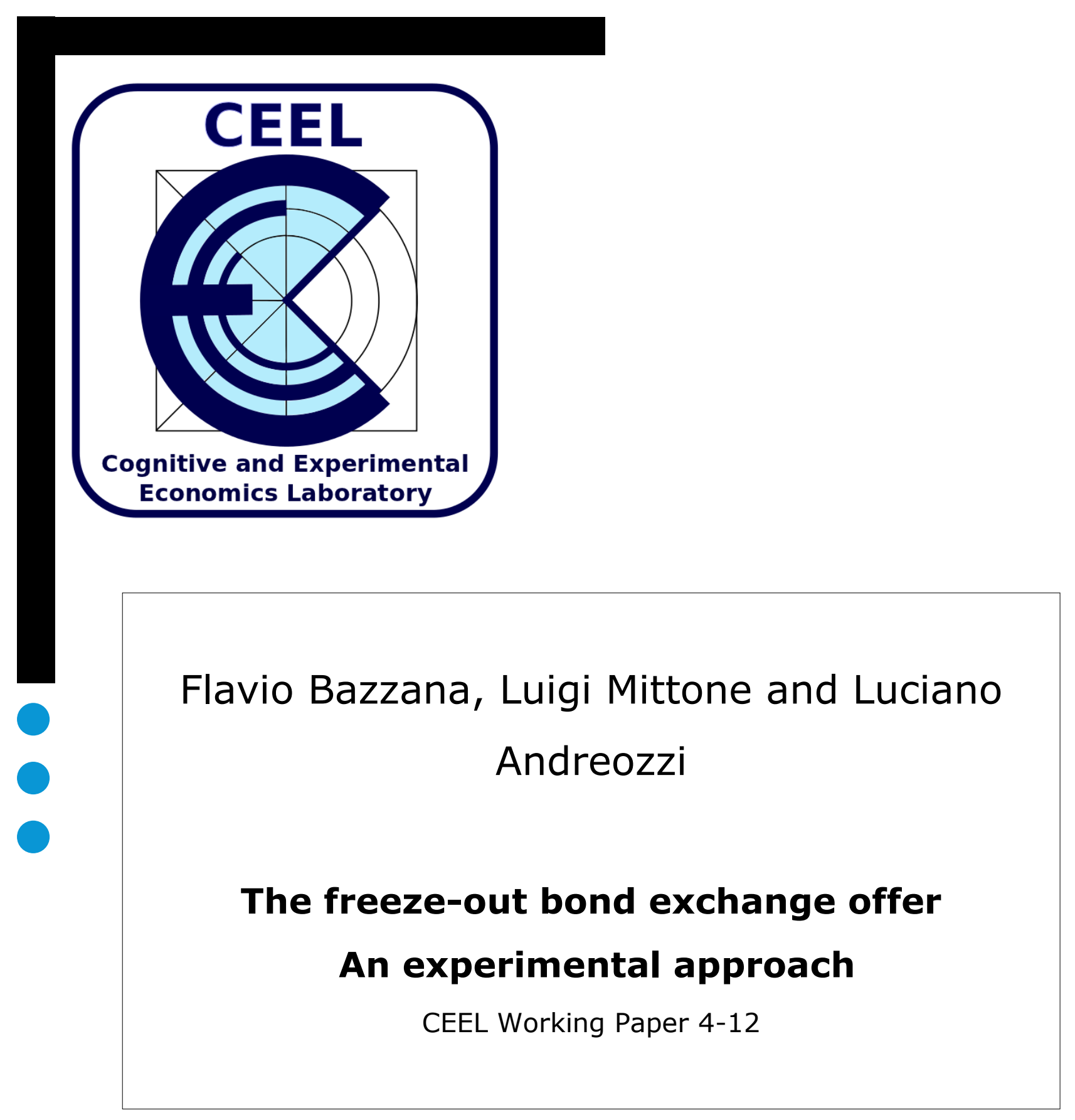

Cognitive and Experimental Economics Laboratory

Via Inama, 538100 Trento, Italy

http://www-ceel.economia.unitn.it tel. +39.461 .282313$ 


\title{
The freeze-out bond exchange offer An experimental approach
}

\author{
Flavio Bazzana, Luigi Mittone, Luciano Andreozzi \\ Department of Economics and Management \\ University of Trento \\ Via Inama, 5 \\ I-38122 Trento ITALY \\ flavio.bazzana@unitn.it \\ ph. +390461283107 fax +390461 282124
}

\begin{abstract}
A freeze-out bond exchange offer can occur when a firm wants to replace an existing bond, issued with a covenant, with a new bond that does not have this type of restriction. If the bondholders are not fully coordinated, the shareholders can make the exchange offer unfair to capture wealth from the bondholders. We perform two experiments using the freeze-out game proposed by Oldfield (2004) to isolate $(i)$ the level of information in the exchange offer and $(i i)$ the role of the experience of the bondholders. The results are statistically significant. In the first experiment, they show that experience is a dominant factor with respect to information. Conversely, in the second experiment, the information becomes dominant with respect to experience. The percentages of the choices for the symmetric Nash equilibria are greater in the first experiment. However, in the second experiment, the choices of the asymmetric Nash equilibrium, which is Pareto superior in the game, are greater than in the first experiment. These results have policy implications that may affect exchange offers in the bond market.
\end{abstract}

JEL classification codes: G32, G12, C91

Keywords: freeze-out, covenant, bond, experimental finance

\section{Introduction}

A freeze-out bond exchange offer can occur when a firm wants to replace an existing bond that has been issued with a covenant with a new bond that lacks this type of restriction. Usually, this happens when the covenant becomes too stringent and limits the choices of the firm. For firms that do not want to modify their business policy, the exchange offer is one of the most commonly used means to avoid violating the covenant, 
i.e., so-called technical default ${ }^{1}$. In the literature, the exchange offer has been analysed mainly for minority shareholders; studies have examined what is commonly referred to as minority freeze-outs (see, among others, Bates et al., 2006). In recent years, some theoretical studies have covered the exchange offer with reference to bonds, and other studies have analysed the coordination problems of debtholders in depth (Bris and Welch, 2005; Hege and Mella-Barral, 2005, Takeda and Takeda, 2008). The empirical research has focused mainly on bond tender² (Mann and Powers, 2007; de Jong et al., 2009) and on motivations for the repurchase of debt (Kruse, et al., 2009). Daniels and Ramirez (2007) analysed the role of covenants more specifically, although the main objective of their study was to evaluate the role of exit consents in exchange offers.

Another important area of study has also emerged in recent years: the difference between covenants for public debt and covenants for private debt. Smith (1993) and Sweeney (1994), among others, noticed the different attitudes toward covenant violations among banks and bondholders. Because private debt covenants are usually stricter than public debt covenants, there is a greater likelihood of covenant violations in private debt than in public debt. Both authors hypothesise that this difference is due to the different degree of coordination of the two classes of creditors. Indeed, for private debt, most creditors are banks, and they are limited in number. For public debt, the number of creditors is significantly higher, and these creditors are mainly noninstitutional investors, which makes it more difficult to reach an agreement in the case of a violation. Thus, the total violation cost is greater. Some empirical studies have documented these differences by comparing public and private debt contracts in terms of the number, variety, and restrictiveness of their covenants (Cotter, 1998; Mather, 1999; Mather and Peirson, 2006). These results have led some authors to search for possible ways to increase the efficiency of bond covenants when the bondholders have a low level of coordination. The first paper that made an effective, practical proposal was Amihud, Garbade, and Kahan (2000). The authors proposed the creation of a "supertrustee" that acts on behalf of the bondholders to "emulate the advantages of private loans - active monitoring, tight covenants and ease of recontracting - while retaining the benefits of liquidity and ease of diversification" (Amihud, Garbade, and Kahan, 2000, p. 116). Recently, Bratton (2006) proposed an amendment to the U.S. legislation on bondholder trustees that would increase the power of action during renegotiation. Additionally, Bazzana and Palmieri (2012) proposed a similar solution for the Italian corporate market.

\footnotetext{
${ }^{1}$ Another way to avoid a technical default is to choose accounting principles that maximize the slack in the debt covenant constraints (see, among others, Paglia and Mullineaux, 2006). In empirical papers, the common use of this policy is considered in the construction of the variables (Achleitner et al., 2012).

${ }^{2}$ Tender offers in the case of share have been discussed in depth in the literature (see the review paper of Burkart and Lee, 2012).
} 
This low degree of coordination when bondholders are large in number can be exploited by the shareholders in an exchange offer and can cause a transfer of wealth in the event of a technical default. Shareholders may issue a new bond with a coupon for less than the equilibrium ones are worth. This outcome is possible because bondholders, having failed to coordinate and act individually, will accept any offer with a coupon greater than the initial bond. An individual choice to refuse an offer may diminish the value of the existing bond if a qualified majority of the bondholders decides to accept the exchange offer. In such a case, the covenants in the original bond will also be cancelled, and the bondholders who have not accepted the exchange offer will suffer a loss of wealth. To avoid this problem when there are coordination difficulties, it is therefore rational to accept the exchange offer, even if it is issued with a coupon value below the equilibrium (Oldfield, 2004). The main objective of our work is to analyse the behaviour of bondholders in a case in which a firm decides to propose an exchange offer to cancel a stringent covenant. This analysis is performed in two experiments using the freeze-out game presented by Oldfield (2004) to isolate two features that are difficult to measure with empirical data: $(i)$ the level of information in the exchange offer and (ii) the role of the experience of the bondholders.

The remainder of the article is organised as follows. In the next section, we analyse the theory underlying the exchange offer, both in terms of bond pricing and in terms of game theory. Then, we describe the experimental design. In the fourth section, we present and discuss the results of the experiment. Our conclusions close the paper.

\section{The theory}

The conflict of interest between shareholders and bondholders can be reduced by inserting appropriate covenants into debt contracts to reduce the transfer of wealth to shareholders. Using this instrument generates certain costs, of which the most important are the violation costs. If a company violates a covenant, the creditor may normally require early repayment or renegotiation. In both cases, the company and the creditors must bear a number of costs, which can reduce the efficiency of covenants (Beneish and Press, 1993).

These costs often occur when the covenant becomes tight, thereby restricting the firm's policy. In this case, the firm can $(i)$ attempt to renegotiate with its creditors or (ii) attempt to replace the bond with a new issue without covenants (in a freeze-out exchange offer). The low level of coordination among the bondholders can produce high renegotiation costs, which make it inconvenient for the firm to renegotiate the debt contract. The firm can only try to replace the existing debt by providing new debt without the protection afforded by the covenant. For a single investor, the minimum condition for the exchange will be that the expected loss of replacement revenue be equal to the expected renegotiation costs. Therefore, the increase in the spread must be 
greater than the loss of protection of the bondholders. The analysis changes significantly if we move from the individual investor to all subscribers of the debt. The firm could, in fact, set the new issue differently, trying to exploit the limited level of bondholder coordination (Oldfield, 2004). Suppose that the firm sets the new bond without a covenant at a lower spread than the equilibrium spread for the individual investor. Accepting the exchange is equivalent to voting favourably for the cancellation of the covenant on the old bond. If the exchange is carried out by a qualified majority of the bondholders, the cancellation of the covenant will affect even the investors who have not agreed to it.

Let us assume that the bond with a covenant that the company wants to replace has a remaining maturity of $n$ years, a fixed annual coupon $c$, and a market price, $p_{\text {old }}$, of 100 , and let us assume that the equilibrium coupon of the new issue, without the covenant, will be $c_{f}=c+b$. Thus, the new bond with maturity $n$ will have the same market value, $p_{\text {new, }}$, as the bond to be exchanged. However, suppose that the company decides to exploit the limited level of coordination among the bondholders to issue a new title with a coupon $c_{u}=c+b-r$, which is slightly lower than the equilibrium rate. The price, if a qualified majority of the bondholders accept the exchange offer, is calculated using the internal rate of return (IRR) of the equilibrium issue as the discount rate:

$$
\left.p_{\text {new }, u}\right|_{>75 \%}=\sum_{i=1}^{n} \frac{f_{u, i}}{(1+c+b)^{t_{i}}}=\sum_{i=1}^{n} \frac{c+b-r}{(1+c+b)^{t_{i}}}+\frac{1}{(1+c+b)^{t_{n}}}
$$

However, the prices of the old and new bonds will be affected by the results of the exchange offer. If a qualified majority of the investors does not accept the exchange, the market price of the old bond will not change. However, because the covenant is not deleted, a minority of the investors (those who have accepted the exchange) will see an increase in the prices of the new title. This is because the new bond comes with a higher coupon and with the protection given by the covenant for the old bond. In this case, we use the same expression using the IRR of the old bond:

$$
\left.p_{\text {new }, u}\right|_{<75 \%}=\sum_{i=1}^{n} \frac{f_{u, i}}{(1+c)^{t_{i}}}=\sum_{i=1}^{n} \frac{c+b-r}{(1+c)^{t_{i}}}+\frac{1}{(1+c)^{t_{n}}}
$$

In contrast, when the exchange is successful, the price of the old bond loses value because the bond loses the protection offered by the covenant. In this case, we use the IRR of the equilibrium issue for the price estimation: that is,

$$
\left.p_{\text {old }, u}\right|_{>75 \%}=\sum_{i=1}^{n} \frac{f_{i}}{(1+c+b)^{t_{i}}}=\sum_{i=1}^{n} \frac{c}{(1+c+b)^{t_{i}}}+\frac{1}{(1+c+b)^{t_{n}}}
$$


Using these results and assuming that $(i)$ the coupon of the original title, $c$, is equal to $4 \%$; (ii) the increase in coupon $b$ for the equilibrium issue without a covenant is equal to $1 \%$; ( iii) the maturity, $n$, is four years; and ( $i v$ ) the reduction of the equilibrium coupon, $r$, is $0.2 \%$, we can obtain the value in Tab. 1 .

\section{Table 1. Bond prices for the single investor}

These values represent the bond prices for the single investor in all four possible cases. We assume the following: (1) the coupon of the original title, $c$, is equal to $4 \%$; $(2)$ the increase in coupon $b$ for the equilibrium issue without a covenant is equal to $1 \%$; (3) the maturity, $n$, is four years; and (4) the reduction in the equilibrium coupon $r$ is $0.2 \%$.

\begin{tabular}{lcc}
\hline \multirow{2}{*}{$75 \%$ of the investors } & \multicolumn{2}{c}{ The $i$-th investor } \\
\cline { 2 - 3 } & Accept & Reject \\
\hline Accept the exchange offer & 99.29 & 96.45 \\
Reject the exchange offer & 102.90 & 100 \\
\hline
\end{tabular}

We can compute the transfer of wealth of a single bondholder by simply looking at the differences between the prices of the bond in the four cases, as follows:

$$
\begin{aligned}
& w_{\text {new },>75 \%}=p_{\text {old }}-\left.p_{\text {new }, u}\right|_{>75 \%} \\
& w_{\text {new },<75 \%}=p_{\text {old }}-\left.p_{\text {new }, u}\right|_{<75 \%} \\
& w_{\text {old },>75 \%}=p_{\text {old }}-\left.p_{\text {old }, u}\right|_{>75 \%}
\end{aligned}
$$

Note that the sign of the second expression is negative in this case because the transfer of wealth will be in the opposite direction, i.e., from the shareholders to the bondholders. These differences are used to define the game in our experiment. We simplify the game by making the differences all positive, which maintains the relationships among the different cases to make the game and the experiment more easily understood.

\section{Figure 1. The three-player freeze-out exchange offer game}

The three players are identified by the capital letters A, B, and C. Player A chooses the row, player $\mathrm{B}$ chooses the column, and player $\mathrm{C}$ chooses the matrix. The outcomes are defined using the simplified differences between the initial price of the bond (100) and the final prices, adding 9 and simplifying to an integer.

B

A

\begin{tabular}{l|c|c|}
\multicolumn{1}{c}{} & Accept & Reject \\
\cline { 2 - 3 } Accept & $7,7,7$ & $7,4,7$ \\
\cline { 2 - 3 } Reject & $4,7,7$ & $9,9,15$ \\
\cline { 2 - 3 } Accept
\end{tabular}

$\mathrm{A}$

Accept
Reject

\begin{tabular}{|c|c|}
\hline Accept & Reject \\
\hline $7,7,4$ & $15,9,9$ \\
\hline $9,15,9$ & $9,9,9$ \\
\hline \multicolumn{3}{|c|}{ Reject } \\
\hline
\end{tabular}

C 
With this simplification, we obtain a simultaneous-moves game in which each player must decide whether to accept or reject the firm's offer. The two matrixes in Fig. 1 represent the players' payoffs. This game has four pure-strategy Nash equilibria, one symmetric and three asymmetric. In the symmetric pure-strategy Nash equilibrium, all players play Accept and receive a payoff of 7 . A single player who switches to Reject obtains 4 . This is the only symmetric equilibrium of the game, as there are no symmetric mixed-strategy equilibria. In all of the asymmetric Nash equilibria, one player accepts, while the other two players reject. In these equilibria, the player who accepts receives a payoff of 15 , whereas the other two players receive 9. It follows that the asymmetric Pareto equilibria dominate the symmetric Nash equilibrium. However, these equilibria require a degree of coordination among the players, as they require one of the players to choose a strategy that is different from the other two. The game is thus a sort of a multiplayer battle of the sexes game in which the asymmetric equilibria are Pareto superior to the symmetric one and players have conflicting preferences.

We then explore the possibility that coordination is achieved by means of cheap talk. Toward this end, consider the following two-stage game. In the first stage, one of the players - for example, A - can make a non-binding announcement concerning the strategy he is going to use. In the second stage of the game, after all players have observed A's announcement, the game will be played. Talk is cheap in this scenario in the sense that the announcement in the first stage does not affect the players' payoffs in the second stage. The literature on cheap talk contains several results that apply directly to our game (see, among others, Blume and Ortmann, 2007). Although the details of the models differ, they all have the same general character. To understand these results, consider the class of simultaneous-moves games $G$ in which there is a Nash equilibrium $s^{*}$ in which a player (call him A) obtains the highest payoff he can obtain from the game. Clearly, the game belongs to this class, as in each asymmetric equilibrium, the player who chooses Accept obtains the highest possible payoff, 15. All the results in this area suggest that if $\mathrm{A}$ is allowed to send a message before the game is played, A can secure his maximum payoff from the game.

Farrell (1988) was the first to show that the Nash equilibrium $s^{*}$ in which A's payoff is maximised is the only sensible (in a technical sense) Nash equilibrium for the cheaptalk version of game $G$. Several papers have reached the same conclusion from an evolutionary perspective. For example, in the evolutionary model proposed by Hurkens (1993), $s^{*}$ is the only set of the game that is closed under rational behaviour. (Blume, 1998 contains a similar result.) More recently, Demichelis and Weibull (2008) proposed an evolutionary model in which the Nash equilibrium $s^{*}$ is the only evolutionarily stable strategy of the game under the hypothesis that agents have a preference for truthtelling. This result is analogous to a similar proposition that was validated in Kim and Sobel (1993).

Although the details of these models differ and the technical proofs can be demand- 
ing, there is a straightforward intuition concerning each of them. When $\mathrm{A}$ is allowed to send a message, he can signal his intention to play his preferred part in the Nash equilibrium. When his message is believable, all other players will play their part in the Nash equilibrium. Additionally, the other players have reason to believe that A will carry out his promise to play his part in $s^{*}$ because in $s^{*}$, A obtains the highest payoff he can obtain from the game.

\section{Experimental design}

We carried out two experiments, each composed of three treatments. These experiments involved 180 students from various faculties of the University of Trento (see Tab. 2). The participants were recruited through announcements on the bulletin board of the laboratory. We registered all students to avoid multiple participation in the experiment. Both experiments were conducted in a computer room equipped in such a way that it did not allow the exchange of information among the players. The seats were randomly assigned. In both experiments, at the beginning of each treatment, the game instructions were both presented on the monitor and read to the players by the instructor (see the Appendix). Despite being given the opportunity to ask questions before each treatment, the players did not ask questions about the game. They only asked for technical information about using the equipment. No student was dismissed for improper behaviour in the classroom experiments. Players were paid immediately after each session in cash. We conducted a pilot of the experiment to verify the participants' comprehension of the instructions and to test the software. The initial instructions were modified according to the result of the pilot.

\section{Table 2. Experiment details}

The first column indicates the number of the experiment. The second column details the treatments, and in the third column, the number of unique players who participate in the two experiments is presented.

\begin{tabular}{ccc}
\hline Experiment & Treatment & \# of players \\
\hline \multirow{2}{*}{1} & 1 & \\
& 2 & 36 \\
2 & 3 & 72 \\
& 1 & 36 \\
& 2 & 36 \\
\hline \multirow{2}{*}{ Total } & 3 & 180 \\
\hline
\end{tabular}

The game underlying the experiments is depicted in Fig. 1. In the first experiment, the same players participated in all three treatments, whereas in the second experi- 
ment, different players were used for each of the three treatments. Each round was played by three players making their choices simultaneously. The participants only had to decide between Accept and Reject. The three treatments differed in the level of additional information available to the players. After every round, the choices and potential payments were communicated to the participants. In addition, in the second treatment, a non-binding announcement was reported before each round. In the third treatment, two non-binding announcements were reported before each round.

The first experiment was conducted with 36 participants. The participants played in all three treatments in sequence. After the first treatment, the participants had played nine rounds, having been divided into groups of three players. The composition of the groups was randomly decided at the beginning of each round. The only change in the second treatment, which was played with the same participants as the first one, was the introduction of new information. At the beginning of each round, one player was randomly selected. This player was forced to inform the other players of his individual choice, although this choice was not binding. Only after this information was presented could the players make their choices. In the third treatment, new information was introduced. At the beginning of each round, two players were chosen randomly. These players were forced to inform the others of their individual choices, but, as before, the announcements were not binding. As in the previous treatment, the players made their choices after these announcements.

Table 3. Outcomes of the first experiment

These values, presented in Experimental Monetary Units, indicate what was paid in the first experiment. The payment to the players was made by extracting a random result from each treatment and summing the value in EMU using the exchange rate $1 \mathrm{EMU}=0,5$ Euros.

\begin{tabular}{lcc}
\hline & \multicolumn{2}{c}{ Your choice } \\
\cline { 2 - 3 } The choices of the other two players & Accept & Reject \\
\hline Every two accept (7 EMU both) & $7 \mathrm{EMU}$ & $4 \mathrm{EMU}$ \\
Every two reject (9 EMU both) & $15 \mathrm{EMU}$ & $9 \mathrm{EMU}$ \\
One accepts and the other rejects & $7 \mathrm{EMU}$ & $9 \mathrm{EMU}$ \\
\hline
\end{tabular}

The payment was made at the end of the experiment. We randomly selected a round from every three treatments and assigned the corresponding values in EMUs (experimental monetary units) according to the values shown in Tab. 3. The sum of every three rounds, converted in Euros ( 1 EMU $=0.5$ Euros $)$, was then paid to the participants.

The second experiment was different from the first in three ways: $(i)$ the number and sample of participants, $(i i)$ the rule for the first treatment, and (iii) the methods of payment and values paid. The second experiment was conducted with 144 participants. We used three different samples for each treatment (Tab. 2). In the first treatment, 72 
players participated in a one-shot round in groups of three players. The payment was made at the end of every treatment according to the values shown in Tab. 4.

\section{Table 4. Outcomes of the second experiment}

These values, in Euros, indicate what was paid in the second experiment. The payment to the players was made for every individual treatment. For the second and the third treatments, the payment was made by extracting a random result.

\begin{tabular}{lcc}
\hline & \multicolumn{2}{c}{ Your choice } \\
\cline { 2 - 3 } The choices of the other two players & Accept & Reject \\
\hline Every two accept $(7 €$ both $)$ & $7 €$ & $4 €$ \\
Every two reject $(9 €$ both $)$ & $15 €$ & $9 €$ \\
One accepts and the other rejects & $7 €$ & $9 €$ \\
\hline
\end{tabular}

In this experiment, we used the values in Euros to provide minimum remuneration to the participants in the first treatment.

In summary, the two identical experiments differ in the role of information. In the first experiment, we have two effects: $(i)$ increasing information for the players and $(i i)$ increasing player experience with the game (because the same players participate in all three treatments). In the second experiment, the available information increases, but there is no experience effect.

\section{Results and discussion}

We first present the outcomes of the experiment in terms of the different equilibria, i.e., in terms of the results of the exchange offer. We then present the results for the single individual choices made by the players.

\section{Table 5. Non-parametric analysis of the two experiments}

Mann-Whitney test of all of the possible combinations of experiments and treatments for the two experiments, not taking into account the announcements made by the players. Significance at the $1 \%, 5 \%$, and $10 \%$ levels is indicated by ${ }^{* * *},{ }^{* *}$, and ${ }^{*}$, respectively.

\begin{tabular}{|c|c|c|c|c|c|c|c|}
\hline \multirow[b]{2}{*}{ Experiment } & \multirow{2}{*}{$\begin{array}{l}\text { Experiment } \\
\text { Treatment }\end{array}$} & \multicolumn{3}{|c|}{ First } & \multicolumn{3}{|c|}{ Second } \\
\hline & & 1 & 2 & 3 & 1 & 2 & 3 \\
\hline \multirow{3}{*}{ First } & 1 & & & & & & \\
\hline & 2 & & & & & & \\
\hline & 3 & $* *$ & & & & & \\
\hline \multirow{3}{*}{ Second } & 1 & & & & & & \\
\hline & 2 & & $* *$ & $* * *$ & & & \\
\hline & 3 & $* * *$ & $* * *$ & $* * *$ & $* * *$ & $*$ & \\
\hline
\end{tabular}

In our first evaluation, we examine the nonparametric analysis of the two experi- 
ments (Tab. 5) without considering the announcements made by the players in the second and third treatments. In the first experiment, the only significant differences are between the first and third treatments, whereas in the second experiment, even the second and third treatments are statistically significant. Thus, we can correctly discuss the differences between the first and second experiment by taking into consideration only the first and the third treatment. If we compare the two experiments, we find that overall, they are different. In particular, the second and third treatments are significantly different, but the first treatment of each experiment is the same. For the latter treatment, after playing a one-shot game or playing the game many times, we obtain the same results.

\section{Table 6. The results of the first experiment}

In the first experiment, the same players participate in all three treatments. The type represents the different possible outcomes of a single round, as detailed using the choices in the second column (Accept, Reject). In the second treatment, one player announces his choice, and in the third treatment, two players announce their choices.

\begin{tabular}{|c|c|c|c|c|c|c|c|}
\hline \multirow{2}{*}{ Type } & \multirow{2}{*}{ Description } & \multicolumn{2}{|c|}{ First treatment } & \multicolumn{2}{|c|}{ Second treatment } & \multicolumn{2}{|c|}{ Third treatment } \\
\hline & & Absolute & Relative & Absolute & Relative & Absolute & Relative \\
\hline 0 & $\mathrm{~A}, \mathrm{~A}, \mathrm{~A}$ & 43 & $39,8 \%$ & 51 & $47,2 \%$ & 62 & $57,4 \%$ \\
\hline 1 & $\mathrm{~A}, \mathrm{~A}, \mathrm{R}$ & 48 & $44,4 \%$ & 41 & $38,0 \%$ & 35 & $32,4 \%$ \\
\hline 2 & $\mathrm{~A}, \mathrm{R}, \mathrm{R}$ & 16 & $14,8 \%$ & 15 & $13,9 \%$ & 10 & $9,3 \%$ \\
\hline 3 & $\mathrm{R}, \mathrm{R}, \mathrm{R}$ & 1 & $0,9 \%$ & 1 & $0,9 \%$ & 1 & $0,9 \%$ \\
\hline Total & & 108 & $100 \%$ & 108 & $100 \%$ & 108 & $100 \%$ \\
\hline
\end{tabular}

Table 7. The results of the second experiment

In the second experiment, different players participate in the three treatments. The 'type' column presents the different possible outcomes of a single round, with the respective choices in the second column (Accept, Reject). In the first treatment, the game is a one-shot game; in the second treatment, one player announces his choice; in the third treatment, two players announce their choices.

\begin{tabular}{|c|c|c|c|c|c|c|c|}
\hline \multirow{2}{*}{ Type } & \multirow{2}{*}{ Descriptions } & \multicolumn{2}{|c|}{ First treatment } & \multicolumn{2}{|c|}{ Second treatment } & \multicolumn{2}{|c|}{ Third treatment } \\
\hline & & Absolute & Relative & Absolute & Relative & Absolute & Relative \\
\hline 0 & $\mathrm{~A}, \mathrm{~A}, \mathrm{~A}$ & 11 & $45,8 \%$ & 38 & $35,2 \%$ & 27 & $25,0 \%$ \\
\hline 1 & $\mathrm{~A}, \mathrm{~A}, \mathrm{R}$ & 11 & $45,8 \%$ & 45 & $41,7 \%$ & 44 & $40,7 \%$ \\
\hline 2 & $\mathrm{~A}, \mathrm{R}, \mathrm{R}$ & 2 & $8,3 \%$ & 17 & $15,7 \%$ & 33 & $30,6 \%$ \\
\hline 3 & $\mathrm{R}, \mathrm{R}, \mathrm{R}$ & 0 & $0,0 \%$ & 8 & $7,4 \%$ & 4 & $3,7 \%$ \\
\hline Total & & 24 & $100 \%$ & 108 & $100 \%$ & 108 & $100 \%$ \\
\hline
\end{tabular}

We can now analyse the results of the two experiments without considering the announcements made by the players in the second and third treatments. If we look at the results of the first experiment (Tab. 6), we see that the choice of the symmetric Nash 


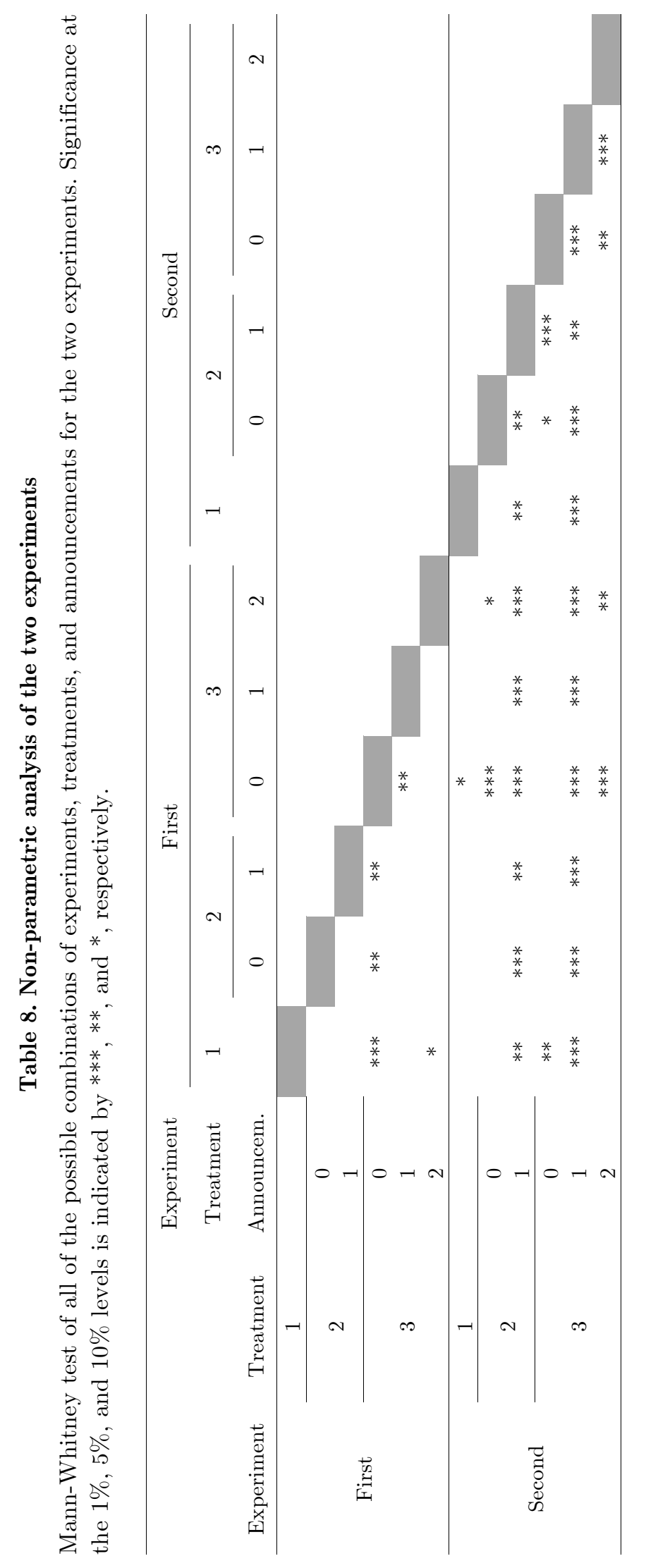


equilibrium (A, A, A) will increase with the treatments, starting from $39.8 \%$ and increasing to $57.4 \%$. Conversely, the asymmetric Nash equilibria (A, R, R) will decline from $14.8 \%$ to $9.3 \%$. We see a double learning effect caused both by playing the game repeatedly and by the announcements.

This result is consistent with that of the repeated experiment on public goods (see Fehr and Gächter, 2000), in which the players tended to increase their choice of the symmetric Nash equilibrium with experience. If we look at the same data for the second experiment, in which three different samples of participants participated in the three treatments separately, we see that the results are significantly different (Tab. 8).

The choice of the symmetric Nash equilibrium decreases with the treatments, starting at $45.8 \%$ in the first treatment and decreasing to $25.0 \%$ in the third. Conversely, the asymmetric Nash equilibrium increases from $8.3 \%$ to $30.6 \%$. This result underlines the role of extra information, i.e., the announcements, which is dominant with respect to the role of experience. A limited number of rounds is insufficient to obtain the effect of the announcements.

Table 9. Relative results of the first experiment

In the first experiment, the same players play all three treatments. The 'type' column presents the different possible announcements by the players as described in the third column (Accept, Reject) for the two treatments using absolute and relative values. In the second treatment, one player announces his or her choice, and in the third treatment, two players announce their choices. The two treatments are played by the same players as the first.

\begin{tabular}{|c|c|c|c|c|c|c|c|}
\hline \multirow{2}{*}{ Treatment } & \multicolumn{3}{|c|}{ Announcement } & \multicolumn{4}{|c|}{ Choices } \\
\hline & Type & Description & $\#$ & Type & Description & Absolute & Relative \\
\hline \multirow{8}{*}{2} & \multirow{4}{*}{0} & \multirow{4}{*}{$\mathrm{A}$} & \multirow{4}{*}{$\begin{array}{c}50 \\
46,3 \%\end{array}$} & 0 & $\mathrm{~A}, \mathrm{~A}, \mathrm{~A}$ & 23 & $46,0 \%$ \\
\hline & & & & 1 & $\mathrm{~A}, \mathrm{~A}, \mathrm{R}$ & 22 & $44,0 \%$ \\
\hline & & & & 2 & $\mathrm{~A}, \mathrm{R}, \mathrm{R}$ & 5 & $10,0 \%$ \\
\hline & & & & 3 & $\mathrm{R}, \mathrm{R}, \mathrm{R}$ & 0 & $0,0 \%$ \\
\hline & \multirow{4}{*}{1} & \multirow{4}{*}{$\mathrm{R}$} & \multirow{4}{*}{$\begin{array}{c}58 \\
53,7 \%\end{array}$} & 0 & $\mathrm{~A}, \mathrm{~A}, \mathrm{~A}$ & 28 & $48,3 \%$ \\
\hline & & & & 1 & $\mathrm{~A}, \mathrm{~A}, \mathrm{R}$ & 19 & $32,8 \%$ \\
\hline & & & & 2 & $\mathrm{~A}, \mathrm{R}, \mathrm{R}$ & 10 & $17,2 \%$ \\
\hline & & & & 3 & $\mathrm{R}, \mathrm{R}, \mathrm{R}$ & 1 & $1,7 \%$ \\
\hline \multirow{12}{*}{3} & \multirow{4}{*}{0} & \multirow{4}{*}{$\mathrm{A}, \mathrm{A}$} & \multirow{4}{*}{$\begin{array}{c}19 \\
17,6 \%\end{array}$} & 0 & $\mathrm{~A}, \mathrm{~A}, \mathrm{~A}$ & 14 & $73,7 \%$ \\
\hline & & & & 1 & $\mathrm{~A}, \mathrm{~A}, \mathrm{R}$ & 5 & $26,3 \%$ \\
\hline & & & & 2 & $\mathrm{~A}, \mathrm{R}, \mathrm{R}$ & 0 & $0,0 \%$ \\
\hline & & & & 3 & $\mathrm{R}, \mathrm{R}, \mathrm{R}$ & 0 & $0,0 \%$ \\
\hline & \multirow{4}{*}{1} & \multirow{4}{*}{$A, R$} & \multirow{4}{*}{$\begin{array}{c}54 \\
50,0 \%\end{array}$} & 0 & $\mathrm{~A}, \mathrm{~A}, \mathrm{~A}$ & 27 & $50,0 \%$ \\
\hline & & & & 1 & $\mathrm{~A}, \mathrm{~A}, \mathrm{R}$ & 20 & $37,0 \%$ \\
\hline & & & & 2 & $\mathrm{~A}, \mathrm{R}, \mathrm{R}$ & 6 & $11,1 \%$ \\
\hline & & & & 3 & $\mathrm{R}, \mathrm{R}, \mathrm{R}$ & 1 & $1,9 \%$ \\
\hline & \multirow{4}{*}{2} & \multirow{4}{*}{$\mathrm{R}, \mathrm{R}$} & \multirow{4}{*}{$\begin{array}{c}35 \\
32,4 \%\end{array}$} & 0 & $\mathrm{~A}, \mathrm{~A}, \mathrm{~A}$ & 21 & $60,0 \%$ \\
\hline & & & & 1 & $\mathrm{~A}, \mathrm{~A}, \mathrm{R}$ & 10 & $28,6 \%$ \\
\hline & & & & 2 & $\mathrm{~A}, \mathrm{R}, \mathrm{R}$ & 4 & $11,4 \%$ \\
\hline & & & & 3 & $\mathrm{R}, \mathrm{R}, \mathrm{R}$ & 0 & $0,0 \%$ \\
\hline
\end{tabular}


We can now analyse the choices by taking into consideration the announcements of the players in the second and third treatments in both experiments. The levels of statistical significance are shown in Tab. 8. If we look at the case of an Accept announcement (A) in the second treatment and a dual Accept announcement (A, A) in the third treatment, we see that the two experiments are not significantly different (Tab. 8). Conversely, in the other cases, the results of the two experiments are significantly different.

That the Accept announcement is chosen in the second treatment in both of the experiments implies that the choices are equally split between the symmetrical Nash equilibria (A, A, A), and of the lower Pareto result (A, A, R). The asymmetric Nash equilibrium (A, R, R) is an unusual choice (see Tab. 9 and Tab. 10).

\section{Table 10. Relative results of the second experiment}

In the second experiment, different players participate in the three treatments. The 'type' column presents the different possible announcements by the players as indicated in the third column (Accept, Reject) for the two treatments with absolute and relative values. In the second treatment, one player announces his or her choice, and in the third treatment, two players announce their choices. The two treatments are played by different players.

\begin{tabular}{|c|c|c|c|c|c|c|c|}
\hline \multirow{2}{*}{ Treatment } & \multicolumn{3}{|c|}{ Announcement } & \multicolumn{4}{|c|}{ Choices } \\
\hline & Type & Description & \# & Type & Description & Absolute & Relative \\
\hline \multirow{8}{*}{2} & \multirow{4}{*}{0} & \multirow{4}{*}{ A } & \multirow{4}{*}{$\begin{array}{c}67 \\
62,0 \%\end{array}$} & 0 & $\mathrm{~A}, \mathrm{~A}, \mathrm{~A}$ & 27 & $40,3 \%$ \\
\hline & & & & 1 & $\mathrm{~A}, \mathrm{~A}, \mathrm{R}$ & 29 & $43,3 \%$ \\
\hline & & & & 2 & $\mathrm{~A}, \mathrm{R}, \mathrm{R}$ & 8 & $11,9 \%$ \\
\hline & & & & 3 & $\mathrm{R}, \mathrm{R}, \mathrm{R}$ & 3 & $4,5 \%$ \\
\hline & \multirow{4}{*}{1} & \multirow{4}{*}{$\mathrm{R}$} & \multirow{4}{*}{$\begin{array}{c}41 \\
38,0 \%\end{array}$} & 0 & $\mathrm{~A}, \mathrm{~A}, \mathrm{~A}$ & 11 & $26,8 \%$ \\
\hline & & & & 1 & $\mathrm{~A}, \mathrm{~A}, \mathrm{R}$ & 16 & $39,0 \%$ \\
\hline & & & & 2 & $A, R, R$ & 9 & $22,0 \%$ \\
\hline & & & & 3 & $\mathrm{R}, \mathrm{R}, \mathrm{R}$ & 5 & $12,2 \%$ \\
\hline \multirow{12}{*}{3} & \multirow{4}{*}{0} & \multirow{4}{*}{$\mathrm{A}, \mathrm{A}$} & \multirow{4}{*}{$\begin{array}{c}30 \\
27,8 \%\end{array}$} & 0 & $\mathrm{~A}, \mathrm{~A}, \mathrm{~A}$ & 18 & $60,0 \%$ \\
\hline & & & & 1 & $\mathrm{~A}, \mathrm{~A}, \mathrm{R}$ & 10 & $33,3 \%$ \\
\hline & & & & 2 & $\mathrm{~A}, \mathrm{R}, \mathrm{R}$ & 2 & $6,7 \%$ \\
\hline & & & & 3 & $\mathrm{R}, \mathrm{R}, \mathrm{R}$ & 0 & $0,0 \%$ \\
\hline & \multirow{4}{*}{1} & \multirow{4}{*}{$\mathrm{A}, \mathrm{R}$} & \multirow{4}{*}{$\begin{array}{c}56 \\
51,8 \%\end{array}$} & 0 & $\mathrm{~A}, \mathrm{~A}, \mathrm{~A}$ & 2 & $3,6 \%$ \\
\hline & & & & 1 & $\mathrm{~A}, \mathrm{~A}, \mathrm{R}$ & 24 & $42,9 \%$ \\
\hline & & & & 2 & $\mathrm{~A}, \mathrm{R}, \mathrm{R}$ & 26 & $46,4 \%$ \\
\hline & & & & 3 & $\mathrm{R}, \mathrm{R}, \mathrm{R}$ & 4 & $7,1 \%$ \\
\hline & \multirow{4}{*}{2} & \multirow{4}{*}{$\mathrm{R}, \mathrm{R}$} & \multirow{4}{*}{$\begin{array}{c}22 \\
20,4 \%\end{array}$} & 0 & $\mathrm{~A}, \mathrm{~A}, \mathrm{~A}$ & 7 & $31,8 \%$ \\
\hline & & & & 1 & $\mathrm{~A}, \mathrm{~A}, \mathrm{R}$ & 10 & $45,5 \%$ \\
\hline & & & & 2 & $A, R, R$ & 5 & $22,7 \%$ \\
\hline & & & & 3 & $\mathrm{R}, \mathrm{R}, \mathrm{R}$ & 0 & $0,0 \%$ \\
\hline
\end{tabular}

If the Accept announcement is popular, i.e., if in the third treatment, every two participants announce that they accept $(\mathrm{A}, \mathrm{A})$, the above results are stronger in both experiments. The choice of the symmetric Nash equilibria (A, A, A) increases, the choice of the lower Pareto (A, A, R) decreases, and the asymmetric Nash equilibrium (A, R, 
$\mathrm{R})$ is not chosen.

If we look at the other announcements, the two experiments are different. In the second treatment of the first experiment, the Reject announcement does not change the result; it is the same as when the Accept is made. In fact, the treatment results are not significantly different (Tab. 8). Conversely, in the second treatment of the second experiment, the Accept announcement is statistically significant, and it changes the results. The symmetric Nash equilibria (A, A, A) declines from $40.3 \%$ to $26.8 \%$, and the asymmetric Nash equilibrium increases from $11.9 \%$ to $22.0 \%$ (Tab. 10).

Looking at the third treatment for both experiments, we see that the most relevant result is an opposite announcement in which one player chooses Accept and the other chooses Reject (A, R). In the first experiment, the symmetric Nash equilibrium is chosen in $50.0 \%$ of the cases. Conversely, in the second experiment, this equilibrium is chosen in only $3.6 \%$ of the cases. The Pareto dominant asymmetric equilibria are chosen in $11.1 \%$ of the cases in the first experiment and in $46.4 \%$ of the cases in the second experiment (Tab. 9 and Tab. 10).

Table 11. Individual choices from the pooled data of the two experiments

The pooled data are generated from the results of the first treatment from the first experiment and the second and third treatments from the second experiment. In the first treatment, no announcements are made by the players; in the second treatment, one player announces his or her choice; and in the third treatment, two players announce their choices. The participants in the three treatments are different players. The rows indicate the individual choice of the player (A, $\mathrm{R}$ in the Play column); the columns indicate the announcement $(\mathrm{A}, \mathrm{R})$ of the first announcer in the second treatment and those of the first and second announcer in the third treatment.

\begin{tabular}{|c|c|c|c|c|c|c|c|c|c|c|c|c|c|c|c|}
\hline \multirow{3}{*}{ Treat. } & \multicolumn{3}{|c|}{ Individual choice } & \multicolumn{6}{|c|}{ First announcer } & \multicolumn{6}{|c|}{ Second announcer } \\
\hline & \multirow{2}{*}{ Play } & \multirow{2}{*}{$\#$} & \multirow{2}{*}{$\%$} & \multicolumn{2}{|c|}{ A } & \multicolumn{2}{|c|}{$\mathrm{R}$} & \multicolumn{2}{|c|}{ Tot. } & \multicolumn{2}{|c|}{ A } & \multicolumn{2}{|c|}{$\mathrm{R}$} & \multicolumn{2}{|c|}{ Tot. } \\
\hline & & & & $\#$ & $\%$ & $\#$ & $\%$ & $\#$ & $\%$ & $\#$ & $\%$ & $\#$ & $\%$ & $\#$ & $\%$ \\
\hline \multirow{2}{*}{1} & A & 241 & $74.4 \%$ & & & & & & & & & & & & \\
\hline & $\mathrm{R}$ & 83 & $25.6 \%$ & & & & & & & & & & & & \\
\hline \multirow{2}{*}{2} & A & 221 & $68.2 \%$ & 55 & $82.1 \%$ & 20 & $48.8 \%$ & 75 & $69.4 \%$ & & & & & & \\
\hline & $\mathrm{R}$ & 103 & $31.8 \%$ & 12 & $17.9 \%$ & 21 & $51.2 \%$ & 33 & $30.6 \%$ & & & & & & \\
\hline \multirow{2}{*}{3} & A & 202 & $62.3 \%$ & 50 & $83.3 \%$ & 25 & $52.1 \%$ & 75 & $69.4 \%$ & 47 & $83.9 \%$ & 23 & $44.2 \%$ & 70 & $64.8 \%$ \\
\hline & $\mathrm{R}$ & 122 & $37.7 \%$ & 10 & $16.7 \%$ & 23 & $47.9 \%$ & 33 & $30.6 \%$ & 9 & $16.1 \%$ & 29 & $55.8 \%$ & 38 & $35.2 \%$ \\
\hline
\end{tabular}

If we look at the individual decisions made by individual players, we also find that information plays an important role in our experiment. To reduce the role of experience, highlighting the role of information, we focus only on the first treatment of the first experiment and on the second and third treatment of the second experiment. This pooled database is more comparable because we have 36 different players for every treatment (see Tab. 2). In general, the trend for all treatments (without regard to the announcements) is to choose Accept, but this option is less popular when information is introduced. In the first treatment, the player accepts in $74.4 \%$ of the rounds, but in the 
second treatment, the value decreases to $68.2 \%$, and in the third treatment, it decreases to $62.3 \%$ (see Tab. 11). These differences, however, are statistically significant only across the first and third treatments (see Tab. 5).

A second observation concerns the degree of consistency between announcements and behaviours. When players decide to Accept, in most cases, they behave in a manner consistent with the announcement (in the second treatment, $82.1 \%$ of people who declared their acceptance actually accepted), and the same is true when two players make announcements. Indeed, the percentage of first announcers in the third treatment who choose Accept and actually accept is $83.3 \%$, and the percentage of second announcers who choose Accept and actually accept is $83.9 \%$. Conversely, when the players choose Reject, the likelihood of consistent behaviour falls. In fact, in the second treatment, only $51.2 \%$ of the players actually follow through. This behaviour remains essentially the same in the third treatment, when only $47.9 \%$ of the first announcers and $55.8 \%$ of the second announcers choose Reject and follow through (see Table 11).

Regarding the frequency of the Accept and Reject announcements (see the column labelled Tot. in Tab. 11), we should note that in both the second and the third treatment, the first players prefer to accept (second treatment, one announcer: Accept 69.4\%, Reject 30.6\%; third treatment, first announcer: Accept $69.4 \%$, Reject $30.6 \%$ ). In the third treatment, with regards to the second announcer, we observe a similar tendency regardless of the actual announcement (Accept $64.8 \%$, Reject $35.2 \%$ ). It is interesting that the effect of the prevalence of Reject announcements is also visible when the first announcer chooses Reject. This behaviour could show that the second announcer believes that he or she cannot have a significant effect on the choices of the other players through his or her announcement strategy. In other words, it would seem that the players attribute little importance to the announcements, except those that are consistent with their beliefs. At the same time, it also appears that the players do not believe that their opponents have confidence in their announcements.

To determine the robustness of our results, we also conduct a logit regression using a pooled database that includes the data from the first treatment (with no announcement) from the first experimental session as well as the second treatment (with one announcement) and the third treatment (with two announcements) from the second experimental session. Our choice of this database is motivated by the need for us to have comparable data for the three treatments regardless of the experimental session. We use a logit regression with random effect to reduce the influence of the imperfectly independent observations. Table 12 shows the results of the regression. 
Table 12. Mixed-effects logistic regression

The dependent variable $(d)$ is a dummy that takes a value of 1 if the participant has refused and 0 if the participant has accepted. The independent variables are as follows: the game round (round); two dummy variables identifying the treatments $\left(t_{1}=1\right.$ for treatment $1, t_{2}=1$ for treatment 2); another dummy variable (announcement) that takes a value of 1 if the participant played the role of the declarant; and two variables that identify the gender (male = 1 if male, 0 if female) and age of the participant $(a g e)$. The random-effects parameter used is the identity of the player. Significance at the $5 \%$, and $10 \%$ levels is indicated by ${ }^{* *}$, and ${ }^{*}$, respectively.

\begin{tabular}{cc}
\hline Variables & Coefficient \\
\hline \multirow{2}{*}{ round } & $-.04727^{*}$ \\
& $(.02896)$ \\
$t_{1}$ & $-.75229^{* *}$ \\
& $(.32589)$ \\
$t_{2}$ & $-.45821^{*}$ \\
& $(.28264)$ \\
announcement & $-.41117^{* *}$ \\
& $(.19566)$ \\
age & $-.06706^{*}$ \\
& $(.04304)$ \\
male & -.09998 \\
constant & $(.22892)$ \\
& $1.4339^{*}$ \\
Number of observations & $(.97715)$ \\
Wald Chi square(6) & 972 \\
Significance & 14.98 \\
\end{tabular}

The only statistically significant explanatory variables at a $5 \%$ level are "t1" and the variable "announcement". These results, given the negative sign of the coefficients, allow us to say that in the first treatment (i.e., in the absence of communication), the probability of rejection decreases for the treatments as information decreases. That is, the probability of acceptance decreases as the information increases. Similarly, it can be concluded that the probability of rejection decreases if the player assumes the role of announcer. This finding indicates that the announcer tends to choose Accept. Both of these results seem consistent with those of the previous data analysis. The results of the regression indicate the robustness of the findings from the experiment.

\section{Conclusion}

A freeze-out bond exchange offer can be used by shareholders to transfer wealth from bondholders if the latter do not coordinate with each other. The lower the level of coordination, the greater the possible transfer of wealth. The difficulty of capturing the 
level of coordination of the bondholders with an appropriate index has limited the empirical analysis of this argument. In theoretical papers, the problem has been correctly defined, but the results are limited to a simple game, with no further analysis of the role of information. In this paper, we close this gap. We conduct two experiments based on a three-player game in which we introduce the role of information and the role of experience. The nonparametric analysis yields statistically significant results that are confirmed by logit regression.

Our first analysis examines the outcome of the game, i.e., the result of the exchange offer. We find different behaviour among the participants in the two experiments. In the first experiment, the experience of the participants is a dominant factor compared to access to information. The choice of the symmetric Nash equilibrium, in which every participant accepts the exchange offer, increases with experience. This result is consistent with the repeated experiments with public goods. Conversely, in the second experiment, which offers a lower level of experience, the information provided is the dominant factor. In this experiment relative to the first one, the choice of the symmetric Nash equilibria decreases, and the choice of the Pareto superior asymmetric Nash equilibrium, in which two participants reject the exchange offer and the other accepts it, increases.

We also analyse the individual choices of the players using a pooled database for the two experiments to reduce the role of experience. We find that in general, the players tend to accept the exchange offer, but this tendency decreases when the availability of information increases. Regarding the players' announcements and behaviour, we should note that consistent behaviour occurs mostly when the player announces that he or she will accept the offer. We also find that the second announcer believes that he or she cannot have a significant effect on the choices of the other players through his or her announcement strategy. It seems that the players attribute little importance to the announcements unless they are consistent with their belief.

These important results have fundamental policy implications. The experiment shows that when there is less available information, the more probable result is the symmetric Nash equilibrium, i.e., the exchange offer will be accepted, and bondholders will experience a transfer of wealth away from them and toward the shareholders. Additionally, experience, which seems to be dominant with respect to information, tends to encourage that outcome. Thus, one possible means to reduce the transfer of wealth in the case of an unfair exchange offer could be to require that bondholders announce their choices prior to the date of the exchange. Because the first announcer seems to impact the final results, the requirement could be enforced by defining who should make this announcement. For example, the first announcer could be the financial institution or the trustee with the largest quote of bonds. The proposed requirement could push firms to reduce, if not eliminate, the degree of unfairness associated with exchange offers. 


\section{Acknowledgements}

We would like to thank Sandro Casal, Ivan Soraperra, and Roberto Gabriele for valuable research assistance. We would also like to thank Kristian Rydqvist and seminar participants at the French Finance Association Conference (AFFI), Montpellier, May 11-13, 2011 and at the Summer School in Psychological Economics and Economic Psychology, Trento, June 22- July 2 for their comments, which were helpful to us as we developed this research. The usual disclaimer applies.

\section{Appendix}

\subsection{First experiment instructions}

\section{Instructions (first treatment)}

Welcome. We kindly ask you to read these instructions carefully and in silence. All communications with other participants are prohibited. Should you have any questions, we ask that you raise your hand. One of the persons in the room will answer your question. Any behaviour intended to disturb the smooth functioning of the experiment will be sanctioned by expulsion from the room without payment.

The experiment allows you to earn a sum in EMU (experimental monetary units). The amount of EMU you earn will depend on your decisions and those of the other participants. Your choices and those of the other participants will never be associated with your name during the experiment. Each of you will interact with two other participants. The identity of the three participants will remain anonymous. Your profit depends on the choice made by all three participants, as indicated in the following table:

\begin{tabular}{lcc}
\hline \multirow{2}{*}{ The choices of the other two players } & \multicolumn{2}{c}{ Your choice } \\
\cline { 2 - 3 } & Accept & Do not accept \\
\hline Both accept $(7$ EMU both) & 7 EMU & 4 EMU \\
Neither accept $(9$ EMU both) & 15 EMU & 9 EMU \\
One accepts and the other does not & 7 EMU & 9 EMU \\
\hline
\end{tabular}

You will need to make nine choices (one for each round), and after each game, we will tell you your result in terms of EMU and reveal which choices were made by all of the other participants. You will always play each round with different players. You will be paid based on the results you have obtained in one randomly selected round of the nine played, with an exchange rate of $1 \mathrm{EURO}=0.5 \mathrm{EMU}$. 


\section{Instructions (second treatment)}

Welcome. We kindly ask you to read these instructions carefully and in silence. All communications with other participants are prohibited. Should you have any questions, we ask that you raise your hand. One of the persons in the room will answer your question. Any behaviour intended to disturb the smooth functioning of the experiment will be sanctioned by expulsion from the room without payment.

The experiment allows you to earn a sum in EMU (experimental monetary units). The amount of EMU you earn will depend on your decisions and those of the other participants. Your choices and those of other participants will never be associated with your name during the experiment. Each of you will interact with two other participants. The identity of the three participants will remain anonymous. Your profit depends on the choices made by all three participants, as indicated in the following table:

\begin{tabular}{lcc}
\hline \multirow{2}{*}{ The choices of the other two players } & \multicolumn{2}{c}{ Your choice } \\
\cline { 2 - 3 } & Accept & Do not accept \\
\hline Both accept (7 EMU both) & $7 \mathrm{EMU}$ & 4 EMU \\
Neither accept (9 EMU both) & $15 \mathrm{EMU}$ & $9 \mathrm{EMU}$ \\
One accepts and the other does not & $7 \mathrm{EMU}$ & $9 \mathrm{EMU}$ \\
\hline
\end{tabular}

A randomly selected participant will communicate his or her choice, which is nonbinding, before the start of the round. Only at this point will all of the players make their choices. You will need to make nine choices (one for each round). After each game, we will tell you your result in terms of EMU and reveal which choices were made by all other participants. You will always play each round with different players. You will be paid based on the results you have obtained in one randomly selected round of the nine played, with an exchange rate of $1 \mathrm{EURO}=0.5 \mathrm{EMU}$.

\section{Instructions (third treatment)}

Welcome. We kindly ask you to read these instructions carefully and in silence. All communications with other participants are prohibited. Should you have any questions, we ask that you raise your hand. One of the persons in the room will answer your question. Any behaviour intended to disturb the smooth functioning of the experiment will be sanctioned by expulsion from the room without payment.

The experiment allows you to earn a sum in EMU (experimental monetary units). The amount of EMU you earn will depend on your decisions and those of the other participants. Your choices and those of the other participants will never be associated with your name during the experiment. Each of you will interact with two other participants. The identity of the three participants will remain anonymous. Your profit depends on the choices made by all three participants, as indicated in the following table: 


\begin{tabular}{lcc}
\hline \multirow{2}{*}{ The choices of the other two players } & \multicolumn{2}{c}{ Your choice } \\
\cline { 2 - 3 } & Accept & Do not accept \\
\hline Both accept (7 EMU both) & $7 \mathrm{EMU}$ & $4 \mathrm{EMU}$ \\
Neither accept (9 EMU both) & $15 \mathrm{EMU}$ & $9 \mathrm{EMU}$ \\
One accepts and the other does not & $7 \mathrm{EMU}$ & $9 \mathrm{EMU}$ \\
\hline
\end{tabular}

A randomly selected participant will communicate his or her choice, which is nonbinding, before the start of the round. A second randomly selected participant will then communicate his or her choice, which is also non-binding. Only at this point will all of the players make their choices. You will need to make nine choices (one for each round). After each game, we will tell you your result in terms of EMU and reveal which choices were made by all of the other participants. You will always play each round with different players. You will be paid based on the results you have obtained in one randomly selected round of the nine played, with an exchange rate of 1 EURO = 0.5 EMU.

\subsection{Second experiment instructions}

\section{Instructions (first treatment)}

Welcome. We kindly ask you to read these instructions carefully and in silence. All communications with other participants are prohibited. Should you have any questions, we ask that you raise your hand. One of the persons in the room will answer your question. Any behaviour intended to disturb the smooth functioning of the experiment will be sanctioned by expulsion from the room without payment.

The experiment allows you to earn a sum in Euros. The amount of Euros you earn will depend on your decisions and those of the other participants. Your choices and those of the other participants will never be associated with your name during the experiment. Each of you will interact with two other participants. The identity of the three participants will remain anonymous. Your profit depends on the choice made by all three participants, as indicated in the following table:

\begin{tabular}{lcc}
\hline & \multicolumn{2}{c}{ Your choice } \\
\cline { 2 - 3 } The choices of the other two players & Accept & Do not accept \\
\hline Both accept $(7 €$ both $)$ & $7 €$ & $4 €$ \\
Neither accept $(9 €$ both $)$ & $15 €$ & $9 €$ \\
One accepts and the other does not & $7 €$ & $9 €$ \\
\hline
\end{tabular}

You will need to make only one choice for only one round. You will be paid based on these results. 


\section{Instructions (second treatment)}

Welcome. We kindly ask you to read these instructions carefully and in silence. All communications with other participants are prohibited. Should you have any questions, we ask that you raise your hand. One of the persons in the room will answer your question. Any behaviour intended to disturb the smooth functioning of the experiment will be sanctioned by expulsion from the room without payment.

The experiment allows you to earn a sum in Euros. The amount of Euros you earn will depend on your decisions and those of the other participants. Your choices and those of the other participants will never be associated with your name during the experiment. Each of you will interact with two other participants. The identity of the three participants will remain anonymous. Your profit depends on the choices made by all three participants, as indicated in the following table:

\begin{tabular}{lcc}
\hline \multirow{2}{*}{ The choices of the other two players } & \multicolumn{2}{c}{ Your choice } \\
\cline { 2 - 3 } & Accept & Do not accept \\
\hline Both accept $(7 €$ both) & $7 €$ & $4 €$ \\
Neither accept $(9 €$ both $)$ & $15 €$ & $9 €$ \\
One accepts and the other doe not & $7 €$ & $9 €$ \\
\hline
\end{tabular}

A randomly selected participant will communicate his or her choice, which is nonbinding, before the start of the round. Only at this point will all of the players make their choices. You will need to make nine choices (one for each round). After each game, we'll tell you your result in Euros and reveal which choices were made by all of the other participants. You will always play each round with different players. You will be paid based on the results you have obtained in one randomly selected round of the nine played.

\section{Instructions (third treatment)}

Welcome. We kindly ask you to read these instructions carefully and in silence. All communications with other participants are prohibited. Should you have any questions, we ask that you raise your hand. One of the persons in the room will answer your question. Any behaviour intended to disturb the smooth functioning of the experiment will be sanctioned by expulsion from the room without payment.

The experiment allows you to earn a sum in Euros. The amount of Euros you earn will depend on your decisions and those of the other participants. Your choices and those of the other participants will never be associated with your name during the experiment. Each of you will interact with two other participants. The identity of the three participants will remain anonymous. Your profit depends on the choices made by all three participants, as indicated in the following table: 


\begin{tabular}{lcc}
\hline & \multicolumn{2}{c}{ Your choice } \\
\cline { 2 - 3 } The choices of the other two players & Accept & Do not accept \\
\hline Both accept $(7 €$ both $)$ & $7 €$ & $4 €$ \\
Neither accept $(9 €$ both $)$ & $15 €$ & $9 €$ \\
One accepts and the others do not & $7 €$ & $9 €$ \\
\hline
\end{tabular}

A randomly selected participant will communicate his or her choice, which is nonbinding, before the start of the round. A second randomly selected participant will then communicate his or her choice, which is also non-binding. Only at this point will all of the players make their choices. You will need to make nine choices (one for each round). After each game, we will tell you your result in Euros and reveal which choices were made by all of the other participants. You will always play each round with different players. You will be paid based on the results you have obtained in one randomly selected round of the nine played.

\section{References}

Achleitner A.K., Braun R., Hinterramskogler B., Tappeiner F. (2012), Structure and Determinants of Financial Covenants in Leveraged Buyouts, Review of Finance, 16 (3), pp. 647-684.

Amihud Y., Garbade K., Kahan M. (2000), An Institutional Innovation to Reduce the Agency Costs of Public Corporate Bonds, Journal of Applied Corporate Finance, 13 (1), pp. 114-21.

Bates T.W., Lemmon M.L., Linck J.S. (2006), Shareholder wealth effects and bid negotiation in freeze-out deals: Are minority shareholders left out in the cold?, Journal of Financial Economics, 81 (3), 681-708.

Bazzana F., Palmieri M. (2012), How to increase the efficiency of bond covenants: A proposal for the Italian corporate market, European Journal of Law and Economics, 34 (2), 327-346.

Beneish M.D., Press E. (1993), Costs of technical violation of accounting-based debt covenants, The Accounting Review, 68 (2), pp. 233-57.

Blume A. (1998), Communication, Risk, and Efficiency in Games, Games and Economic Behaviour, 22, 171-202.

Blume A., Ortmann, A. (2007), The effects of costless pre-play communication: Experimental evidence from games with Pareto-ranked equilibria, Journal of Economic Theory, 132 (1), 274-290

Bratton W.W. (2006), Bond Covenant and Creditor Protection: Economics and Law, Theory and Practice, Substance and Process, European Business Organization Law Review, 7 (1), pp. 39-87.

Bris A., Welch I. (2005), The Optimal Concentration of Creditors, The Journal of Fi- 
nance, 60 (5), 2193-2212.

Burkart M., Lee S. (2008), One Share - One Vote: the Theory, Review of Finance, 12 (1), pp. 1-49.

Cotter J. (1998), Utilisation and restrictiveness of covenants in Australian private debt contracts, Accounting and Finance, 38 (2), 181-196.

Daniels K., Ramirez G. (2007), Debt restructurings, holdouts, and exit consents, Journal of Financial Stability, 3 (1), 1-17.

de Jong A., Roosenboom P., Schramade W. (2009), Who benefits from bond tender offers in Europe? Journal of Multinational Financial Management, 19 (5), 355-369.

Demichelis, S., Weibull, J.W. (2008), Language, meaning and games: a model of communication, coordination and evolution, American Economic Review., 98 (4), 12921311

Farrell J. (1988), Communication, coordination and Nash equilibrium, Economics Letters, 27 (3), pp. 209-214

Fehr E., Gächter, S. (2000), Cooperation and Punishment in Public Goods Experiments, The American Economic Review, 90 (4), pp. 980-994.

Hege U., Mella-Barral P. (2005), Repeated Dilution of Diffusely Held Debt, The Journal of Business, 78 (3).

Hurkens S. (1993), Coordination Failure and Endogenous Timing, in Operations Research '92, eds. Karmann A., Mosler K., SchaderM., Uebe G., 419-421.

Kim, Y., Sobel, J. (1995), An Evolutionary Approach to Pre-Play Communication, Econometrica, 63 (5), pp. 1181-1193

Kruse T., Nohel T. and Todd S.K. (2009), The Decision to Repurchase Debt, mimeo.

Mann S., Powers E. (2007), Determinants of bond tender premiums and the percentage tendered, Journal of Banking and Finance, 31 (3), 547-566.

Mather P., Peirson G. (2006), Financial covenants in the markets for public and private debt, Accounting and Finance, 46 (2), pp. 285-307.

Mather P.R. (1999), Financial covenants in Australian private debt contracts: incidence, measurement rules and monitoring, Australian Accounting Review, 9 (17), 6372 .

Oldfield G.S. (2004), Bond Games, Financial Analysts Journal, 60 (3), pp. 52-66.

Paglia J.K., Mullineaux D.J. (2006), An empirical exploration of financial covenants in large bank loans, Banks and Bank Systems, 1 (2), 103-122.

Smith C.W. (1993), A perspective on accounting-based debt covenant violations. The Accounting Review, 68 (2), pp. 289-303.

Sweeney A.P. (1994), Debt-covenant violations and managers' accounting responses, Journal of Accounting and Economics, 17 (May), pp. 281-308.

Takeda F., Takeda K. (2008), How Large Creditors Affect Corporate Bond Prices through Creditor Coordination, Journal of International Economic Studies, 23, 3149 . 